\title{
Review Article \\ Probabilistic Evaluation of Service Life for Reinforced Concrete Structures
}

\author{
Sanjeev Kumar Verma, ${ }^{1}$ Sudhir Singh Bhadauria, ${ }^{2}$ and Saleem Akhtar ${ }^{1}$ \\ ${ }^{1}$ Civil Engineering Department, University Institute of Technology, Rajiv Gandhi Technological University, \\ Airport Road Bhopal, Madhya Pradesh 462036, India \\ ${ }^{2}$ S. G.S. Institute of Technology and Science, Indore, Madhya Pradesh 452003, India
}

Correspondence should be addressed to Sanjeev Kumar Verma; sanjeev.apm@gmail.com

Received 13 December 2013; Accepted 8 January 2014; Published 18 February 2014

Academic Editors: I. Smith and X. Zhou

Copyright (C) 2014 Sanjeev Kumar Verma et al. This is an open access article distributed under the Creative Commons Attribution License, which permits unrestricted use, distribution, and reproduction in any medium, provided the original work is properly cited.

Degradation of performance and deterioration of different components of reinforced concrete (RC) structures increase with the age of structure. This deterioration of reinforced component depends on several parameters. However, modeling service life of RC structure by considering all the parameters is a difficult job, as most of the parameters are uncertain in nature. Probabilistic models account well for the uncertainties in the parameters responsible for deterioration of RC structures. This paper presents a review of several recent service life models developed using probability based concepts.

\section{Introduction}

Performance and service life of a RC structure are governed by several parameters such as strength, quality of concrete, concrete cover, age, and most significantly by exposure conditions. According to Li et al. [1] behavior or performance of concrete structures depends on various physical and chemical related phenomena but it is hard to combine various analytical models in order to simulate real degradation process. Hence, because of random nature of the parameters governing the performance of RC structures, probabilistic approach is better to develop reliable service life prediction model. Probabilistic models calibrated with monitored field data can provide more reliable models to predict the probabilities of corrosion. This category includes models based on probability or statistical concepts such as probability function, reliability based models, Monte Carlo simulation, Markov chain methods, and fuzzy logic. In probablistic analysis three steps can be distinguished: (a) definition of failure modes (limit states) and corresponding models, (b) quantification of the statistics of the random variables, and (c) calculation of the desired results as, for instance, failure probabilities [2]. Present paper reviewed several probability based service life models developed by researchers for evaluating the probability of failure and estimating the residual life of RC structures.

\section{Service Life}

Service life of a RC structure can be defined as time period during which structure will fulfill the required performance under defined repair and maintenance. Zhang and $\mathrm{Ba}$ [3] defined service life as the life before critical chloride concentration led to reinforcement corrosion. According to Chai et al. [4] period from initial use to depassivation can be considered as service life. Vorechovska et al. [5] considered depassivation of reinforcement due to carbonation or chlorination as the end of service life. Parameswaran et al. [6] considered the time during which the performance of a concrete structure will be kept at a compatible level to fulfill the performance as service life, provided that it is properly maintained. Rostam [7] defined service life as the number of years during which the structure shall perform satisfactorily without unforeseen high costs for maintenance. MartinPerez and Lounis [8] defined service life as the time until damage accumulation reaches an unacceptable or limit state. According to Abu-Tair et al. [9] end of service life is reached 


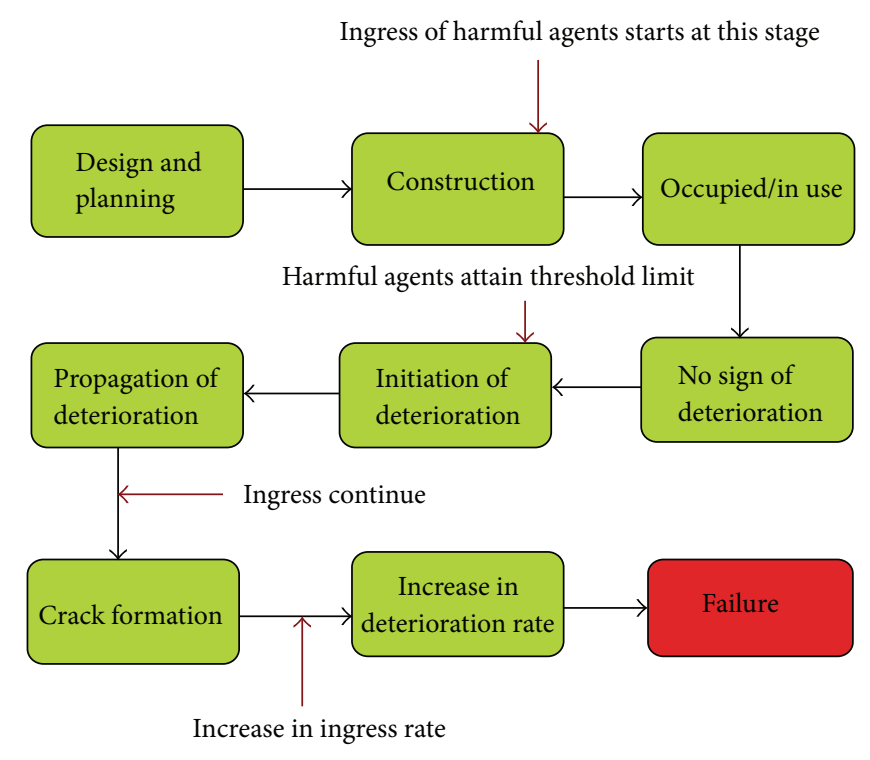

FIGURE 1: Different levels of service life.

when either failure occurs or major repair is necessary to keep the structure in service. Teply [10] described service life as the period of time after installation during which all the conditions of the structure meet or exceed the performance. Different levels in service life of a RC structure are presented in Figure 1; these levels are design, construction, in use, period without any deterioration, initiation of deterioration, propagation of deterioration, formation of cracks, rapid deterioration, and finally failure of structure.

According to Figure 1, after design and construction when structure is in use before the initiation of deterioration, there is a phase with no sign of deterioration. Ingress of harmful agents will get initiated during the construction level and continuous during no deterioration level. When ingress of theses harmful agents reaches the threshold limit then it initiates deterioration of RC structures; this deterioration further propagates and reduces the performance of RC structure. Deterioration propagates and finally results in formation of cracks; these cracks allow more ingress of harmful agents and further increases the deterioration at a faster rate. Finally this increase in deterioration rate reduces the performance and finally causes the failure of structure.

For modeling the performance of RC structures several parameters such as environmental effects, degradation mechanisms, durability parameters, and properties of ingredients are required to be considered. Defining the failure of structure is most important for modeling the service life. Failure of a concrete structure can be simply explained on the basis of load " $L$ " and capacity " $C$." $L$ and $C$ are any destructive effect and resistive capacity. If $L$ is the environmental effect, $C$ is the capacity to resist the environmental effects. Hence if $L$ is greater than $C$, this condition will represent the failure of structure " $F$ ":

$$
\{F\}=\{C<L\}
$$

Therefore probability of failure Pf can be defined as

$$
\text { Pf }=P\{C<L\} .
$$

\section{Several Probabilistic Performance Models}

Probabilistic models account well for the uncertainties in the parameters responsible for deterioration of RC structures. Hence, several researchers applied probability concepts for developing performance models. Orcesi and Frangopol [11] implemented a model using the lifetime functions to evaluate a probability of survival of bridge components. The possible outcomes assossiated with nondestructive inspections (NDIs) are incorporated in an event tree model. Use of life time function for each component of the structural system enables to express the probability that the component survives and also provided a practical methodology for determining optimal NDIs for different components of steel bridges. The expression of the survival function $(S)$ is shown in the following equation:

$$
S(t)=1-F(t)=P(T>t)=\int_{t}^{\infty} f(u) d u
$$

where $S$ is the lifetime function that represents the probability that structure will not fail before time $t . F$ is the represents the probability that the structure fails before time $t . T$ is the time to failure. $f$ is the probability density function. Cusson et al. [12] presented the development of probablistic mechanistic modeling approach supported by durability monitoring to obtain improved predictions of service life of concrete bridge decks exposed to chlorides. Factors influencing the service life are (i) surface chloride content $C_{s}$, (ii) chloride diffusion coefficient $D$, (iii) threshold chloride content $C_{\text {th }}$, (iv) corrosion rate and deterioration rate.

Agarwal et al. [13] described an approach based on Weibull distribution to calculate the deterioration rates of typical bridge elements using historical bridge inspection data and compare the results with those, using the traditionally used Markov chains approach. This approach has been incorporated into a computer program that generates the deterioration curves for bridge elements, based on historical bridge inspection data and described a 7-scale condition rating used to calculate the deterioration rates for each bridge element. Bridge condition rating scale ranges from 7 to 1 , 7 being new and 1 being failed condition. Mitra et al. [14] developed method for obtaining condition index of corrosion distressed RC building using concepts of fuzzy logic and integrates visual inspection with in situ investigations for carbonation and chloride content. Visual assessment is a two stage process: (i) visual survey has been conducted to gain information about physical and chemical state and by recording visible signs of deterioration such as cracks, rust stains, and spalling colour; (ii) condition has been assessed by an expect based on the information obtained in first stage. Vorechovska et al. [5] presented the service life assessment utilizing durability limit states specialized for concrete structures. Both initiation and propagation periods of reinforcement corrosion are considered and comprehensive 
choice of limit states is provided. The approach is based on degradation modelling and probablistic assessment.

Strauss et al. [15] introduced a reliability assessment of RC structures and demonstrated real existing bridge structures. Reliability index of the structure decreases during its life cycle due to material degradation. This procedure is modeled by advanced life cycle computer simulation. Analytical deterioration models combined with in situ monitoring are used to launch the degradation process. Main feature of the presented approach is the nonlinear finite element analysis of the structure. Marano et al. [16] developed a probability based methodology to use the traditional theories for reliability assessment and proposed an efficient approach for timedependent reliability analysis regarding RC beams subjected to pitting corrosion. Steel bars pitting corrosion has been an electrochemical process that could seriously degrade the $\mathrm{RC}$ structures. Consequences of pitting corrosion process on structural safety are more serious than due to general corrosion. Tesfamariam and Martín-Pérez [17] proposed a probablistic based model for carbonation induced corrosion based on Bayesian belief network (BBN); this proposed model is compared with more traditional probablistic technique, Monte Carlo simulation. This BBN model estimates carbonation depth and consequently determines the probability of onset of corrosion. Commonly available information of environmental exposure condition, mix design information, and in situ nondestructive testing measurements have been integrated to determine the potential for carbonation indused corrosion. For carbonation induced corrosion, service life is the time for the carbonation front to reach the reinforcing steel depth. Relation between carbonation depth and exposure time is given in the following equation:

$$
x=k t^{(1 / m)} \text {, }
$$

where $x$ is carbonation depth, $k$ is carbonation constant, $t$ is time of exposure, normally $m$ is 2 . Sobhani and Ramezaninpour [18] developed an algorithm to extract the fuzzy membership functions from the available stochastic information and also proposed an integrated system to convert the probablistic information into the corresponding fuzzy sets. Under environmental conditions of high aggressiveness, even concrete which has been properly prepared and placed may loose its protective properties and allow for corrosion of reinforcement. Corrosion of reinforcement involves some uncertainties: (1) random nature of corrosion process and (2) linguistic terms of construction process.

Melchers et. al [19] proposed an approach for strength and performance deterioration modeling of RC structures exposed to saline or marine environment, based on theoretical concepts and probability. At present there is little field experience and other data available, so probablistic modeling has been proposed here. This has been based on the evidence that the rate of diffusion of chlorides is influenced by internal damage to the concrete surrounding the reinforcement. The proposed procedure has been applied to an example beam and compared to experimental observations, including estimates of uncertainty in the remaining ultimate moment capacity and beam stiffness. Val [20] examined the effect of corrosion of reinforcing steel on flexural and shear strength and on the reliability of reinforced concrete beams. Probability of failure has been evaluated using Monte Carlo simulation. Uncertainties in material properties, geometry, loads, and corrosion modeling are taken into account. Two types of corrosion general and pitting have been considered and more emphasis has been on pitting corrosion. Results show that pitting corrosion has a significant influence on the reliability of RC beams. Anoop and Balaji Rao [21] demonstrated that the use of data from field inspections for performance evaluation and remaining life assessment of corrosion affected RC bridge girders using the concept of additive fuzzy logic; remaining life of the member can be assessed by determining the time taken for a given performance measure to deteriorate to a target value. Corrosion initiation time is determined using Fick's 2nd law of diffusion. Uncertainties in the values of the parameters characterizing the environment and variables affecting the time to corrosion initiation and corrosion propagation are taken into account by treating them as fuzzy variables. Usefulness of proposed methodology has been illustrated through a case study, by comparing the time to reach different damage levels for a severely distressed beam. Shao and $\mathrm{Li}$ [22] formulated an asset management strategy based on risk cost optimization for infrastructure during its whole service life. Time-dependent reliability method is used to determine the probability of attaining each phase of the service life. An algorithm is developed for above formulation and programmed in a userfriendly manner. To maintain the safety and serviceability of a structure during its service life, intermediate maintenance for the structure has been necessary. Li and Vrouwenvelder [2] showed the service life prediction procedure including advanced spatial variability approach, which implements the random spatial variation of property differences across the structure. Most parameters involved in deterioration of RC structures subjected to corrosion are random, so probability based reliability analysis is often applied. In probablistic analysis three steps can be distinguished: (a) definition of failure modes (limit states) and corresponding models, (b) quantification of the statistics of the random variables, and (c) calculation of the desired results as, for instance, failure probabilities. Chloride ingress is modeled using Fick's 2nd law of diffusion.

Sasmal et al. [23] explored the possibilities of using fuzzy mathematics for condition assessment and rating of bridges and developing a systematic procedure and formulations for rating existing bridges using fuzzy mathematics. Fuzzy logic is a means for modeling the uncertainty involved in describing an event result using natural language; it is useful for remedying the uncertainties and imprecision. Computer programs developed from formulations presented in this paper have been used for evaluating the rate of existing bridges.

Li et al. [24] presented a performance based methodology for serviceability assessment of corrosion affected concrete structures. Methods of time-dependent reliability are employed to quantify the probability of serviceability failure. Merit of the developed methodology has been identified as the structural response has been directly related to design 
criteria used by structural engineers and asset managers. It has been found that, under the same service conditions, corrosion-induced cracking attains a serviceability limit state before deflection does. In the theory of structural reliability the criterion can be expressed in the form of a limit state function as follows:

$$
G(L, S, t)=L(t)-S(t)
$$

where $S(t)$ denotes the response of structure at time $t$, such as stresses and deformation; and $L(t)$ denotes a critical limit for structural response, which may change with time but in most practical use it is a constant prescribed in the design codes. With the limit state function of (5), the probability of serviceability failure, ps, can be determined by

$$
\operatorname{ps}(t)=P[G(L, S, t) \leq 0]=P[S(t) \geq L(t)] \text {. }
$$

Kong and Frangopol [25] simulated time-varying performance of deteriorating materials and structures using probabilistic methods. Evaluation of the time-varying performance of deteriorating materials and its effect on structures measured by the reliability index profile is addressed based on three aspects: (1) acquisition of statistical characteristics of input random variables from imperfect samples, (2) model-based simulation, and (3) evaluation of variability and sensitivity measures of the nondeterministic performance model. Vu and Stewart [26] developed a 2D spatial timedependent reliability model to predict the likelihood and extent of corrosion-induced cracking. The spatial variability of concrete cover, concrete compressive strength, and surface chloride concentration is considered in the spatial timedependent reliability model. The reliability analysis predicts (1) probability of the first incidence of cracking, (2) proportion of an area subject to severe cracking, and (3) probability that a given percentage of a concrete surface has cracked. The time to severe cracking has been referred to the time when concrete cover cracking reaches a limit crack width and has been estimated based on results from accelerated corrosion tests of RC slabs. The corrosion-induced cracks occurred on the concrete surface above and parallel to the rebars. The various stages of crack growth can be represented in Figure 2, where time to excessive cracking can be described in two stages: (1) crack initiation ( $t 1$ ), time to first cracking (hairline crack of $0.05 \mathrm{~mm}$ width), (2) crack propagation ( $t 2)$; time for crack to develop from first cracking to a limit crack width.

Akgül and Frangopol [27] presented a probablistic framework forecasting the lifetime performance of RC slabs and girders of bridges. Bridges have been individually described followed by presentation of the performance analysis results including both initial reliability indices and lifetime reliability profiles. Computer program RELNET (reliability of system network) has been used to perform reliability analysis for the bridges. Special emphasis has been given to chloride penetration in RC. Use of Fick's 2nd law of diffusion for modeling the chloride penetration has been explained. Val [28] presented a reliability-based method for the evaluation of the expected cost of failure of RC structures subject to chloride-induced corrosion, and penetration of chloride into concrete is studied by Fick's 2 nd law of diffusion.

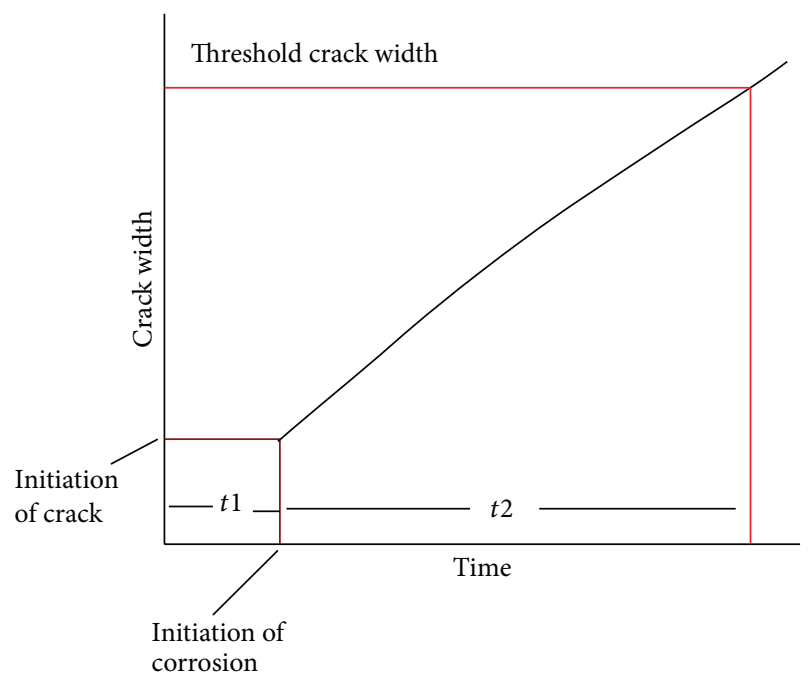

FIGURE 2: Crack initiation and propagation based on concept of $\mathrm{Vu}$ and Stewart [26].

The resistance degradation function introduced has been used to calculate the probability of failure of corrosiondamaged RC elements for such typical ultimate limit states as flexure, shear, and compression. In this study only the most essential parameters, which govern the deterioration process associated with corrosion, have been considered. These include concrete grade and thickness of the concrete cover (structural parameters) and the surface chloride content (environmental conditions).

Martin-Perez and Lounis [8] presented an approach for service life prediction of RC structures exposed to chloride environment that combines a FE modeling of the chloride transport and a reliability-based analytical method for onset of damage and its accumulation. By using Monte Carlo simulation the probabilistic distributions of the chloride penetration front and corrosion initiation time are generated. A stochastic deterioration process for corrosion initiation and propagation and then crack initiation and propagation have been used to examine the effect of cracking, spalling, and loss of reinforcement area on structural strength and reliability by Stewart and Val [29] and also presented models for reliability and life cycle cost analyses of reinforced concrete bridges damaged by corrosion. Monte Carlo simulation analysis is then used to determine probabilistic time-dependent estimates of structural performance, such as resistance and reliability of serviceability and strength limit states, for a typical $\mathrm{RC}$ slab bridge. In the present analyses it is assumed that corrosion, dimensional, and material variables are homogeneous over the structure so spalling damage will also be initiated homogeneously over the deck area. Li [30] proposed a performance-based model of life cycles of corrosion affected $\mathrm{RC}$ structures with the focus on the effect of propagation of reinforcement corrosion on structural deterioration, corrosion propagation that leads to structural deterioration which is of most concern to structural engineers. Results produced from a comprehensive experiment designed to investigate the corrosion propagation in concrete and its effect on the deterioration of structural strength and stiffness have been 
presented and analyzed. An assessment criterion has been established to define the structural performance in terms of strength and serviceability limit states that are consistent with design criteria. A comparison of the experimental results on strength deterioration as determined from destructive load test and nondestructive measurement of corrosion current density has also been undertaken. In addition, the proposed model is on a probabilistic basis. A performance-based assessment criterion needs to be established:

$$
P[R(t) \geq \mathrm{Ra}\} \geq \mathrm{pa},
$$

where $P$ is probability of an event and $R(t)$ is structural resistance varying with time $t$, that is, deterioration; $\mathrm{Ra}$ is minimum acceptable resistance and pa is minimum acceptable probability of structural safety, that is, structural reliability. Detection of the initiation of corrosion in steel bars denotes the beginning of whole life performance assessment for RC structures. Li [31] emphasize on the development of a reliability-based method to estimate the initiation time of reinforcement corrosion in concrete structures. Detection of the initiation of corrosion in reinforcement marks the beginning of whole life performance assessment for RC structures. Failure does not necessarily mean structural collapse only, but also includes loss of serviceability, characterized by concrete cracking, spalling, and excessive deflection. Merit of developed models is that they are derived from data representing concrete structures in real service conditions.

Liang et al. [32] adopted multiple layer fuzzy theory to evaluate the state of existing RC bridges. The damage state of any member of an existing bridge has been systematically and completely composed as an evaluation model of multiple layer fuzzy mathematics. The evaluated results may be used for the safety index and reference index for repair or reinforcement in existing bridges. In addition, the evaluated results may also be used as a design reference for service life in future bridge building. The evaluated bridges have been categorized into the grades I, II, III, IV, and V, which are described as nondamage, light damage, moderate damage, severe damage, and unfit for service, respectively. Teply [10] applied a probabilistic approach to predict the service life of concrete structures for modeling the deterioration effects. Mathematical models can be made for the performances of a building or structure, including the process of ageing (deteriorating). Generally two classes of problems may be distinguished in this context: (i) prediction of service life for structures during the design process. This becomes a necessity in the context of the new "performance-based design" rules, which are a trend in forthcoming engineering work; (ii) assessment of existing structures, that is, estimating residual service life. Figure 3 shows the probabilistic representation of service life comparing influence of the load $S$ and a function for the load bearing capacity $R$ (or the structural resistance function). Alternatively, the service life of reinforced concrete structures may be assessed by distinguishing two periods. First, the initiation period, during which the gradual depassivation of the reinforcing bars (due to $\mathrm{CO}_{2}$ or other effects) is in progress. Second, the propagation period, during which corrosion of the reinforcement takes place, and, consequently,

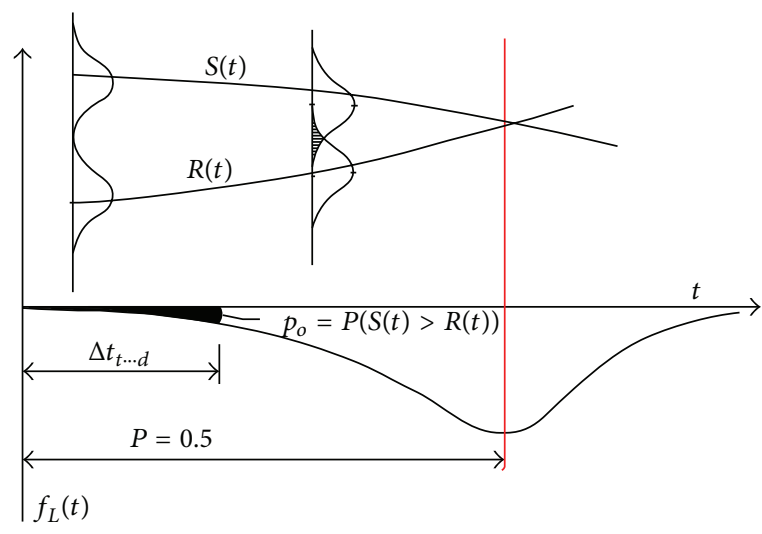

FIgURe 3: Probabilistic structural service life by Teply [10].

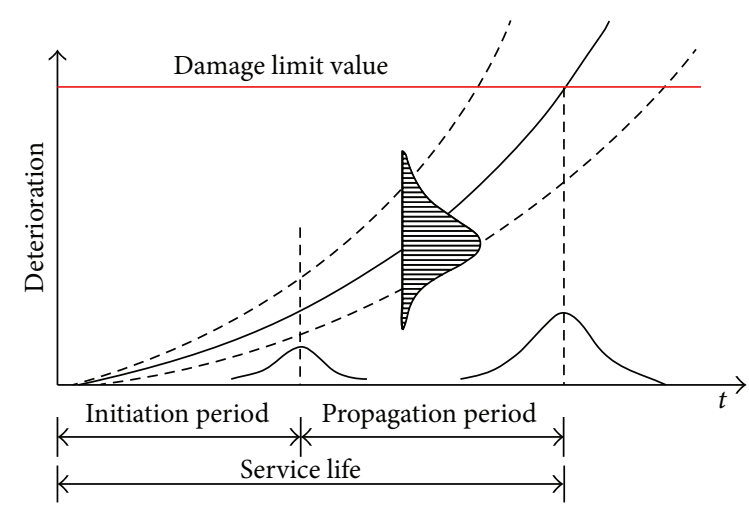

Figure 4: Two periods of structural service life by Teply [10].

the failure probability is increased for both the load and serviceability limit states; this is illustrated in Figure 4.

Gulikers [33] presented a model which takes into account the accelerating effect of macrocells on local corrosion rates assuming a cylindrical shape of the pitting site; results are presented in terms of local penetration depth, surface area under corrosion attack, and steel volume consumed by corrosion. The improved corrosion deterioration model can be used to develop a probabilistic model which allows for evaluation of the probability that a given reduction of the reinforcement cross-section has taken place at a given time. Abu-Tair et al. [34] highlighted the importance of developing service life prediction models for the risk of degradation of reinforced concrete structures so that optimal strategies for their maintenance and repair can be developed; data on bridge deterioration of over 400 bridges will be used to provide predictive models based on the factor method. $\mathrm{Vu}$ and Stewart [35] measured service life of structures exposed to aggressive environments by the probability of cracking and spalling of concrete cover; time to corrosion/spalling is found experimentally from accelerated corrosion testing of RC slabs, emphasis to quantify the relationship between concrete quality ( $w / c$ ratio or strength), concrete cover, crack propagation, and time. Proportion of a concrete surface likely to spall for any reference period can be predicted by reliability 
model. This is a useful criterion for predicting the service life of RC structures.

The MCSC (Monte Carlo simulation for corrosion) computer program has been used to evaluate the probability density function of the corrosion initiation time for the steel reinforcement by Enright and Frangopol [36], for the bridge girders with particular attention to Colorado bridges. The corrosion initiation time is distributed log normally and is increasing with the depth of concrete cover. A survey on degradation mechanisms is briefly presented. Damage has been reviewed for a variety of bridges based on information collected from the literature and from field studies performed by the Department of Transportation, Colorado. The scope of this investigation has been limited to concrete bridges subjected to environmental attack. Method for predicting strength loss has been applied to a typical bridge in Colorado. The results can be used to identify critical elements for inspection and repair and to assist in the development of rational maintenance planning strategies for concrete bridges. The strength degradation mechanisms can be classified as affecting either the concrete or the steel reinforcement or both. Concrete deteriorates because of internal pressures, which have been caused primarily by chemical reactions in the cement (sulfate attack), by chemical reactions between the cement and aggregate (alkali-silica reaction), or by freezethaw cycle attack.

According to Naticchia [37] building behavior depends on various physical and chemical phenomena related to each other, but it is hard to combine many numerical models in order to simulate real behavior of degradation process. In order to find ideal strategy, a model is proposed based on "qualitative simulation approach" capable to represent the interrelated decay phenomena, so an approach is proposed based on Bayesian belief networks, assembling all phenomena. Scheremans and Gemert [38] updated a probability based model for interpretation of test results and prediction of the service life of RC structures. Ingress of chloride ions into the pores of the concrete is caused by diffusion and evaluated using Fick's 2nd law of diffusion. Teply et al. [39] described a probabilistic approach for investigating the reliability and predicting life time of simply supported RC beams including deterioration in time. Only the ultimate limit state is controlled and depassivation of reinforcing bars is supposed to be caused by carbonation of concrete. Enright and Frangopol [40] combined inspection results with prior information using Bayesian updating and used this approach for determining corrosion initiation time and rate on time-variant strength. This study illustrated a method for computing strength degradation using a probabilistic approach, updated by Bayesian's method.

Cheung and Kyle [41] described the development and application of reliability-based system for the service life prediction and management of maintenance and repair procedures of RC structures. This system is capable of establishing levels of reliability by using statistical databases and probability theory, for satisfying various governing conditions (limit states) required for determining performance and financial considerations. The reliability of a structure or component has been defined as its probability of survival
(Ps), which is related to probability of failure (Pf) as in (8):

$$
\text { Ps }=1-\text { Pf. }
$$

Mori and Ellingwood [42] presented a probability based method to evaluate time-dependent reliability of components and systems of reinforced or prestressed concrete structures. These methods enable the impact of uncertainties in loading condition, structural strength, and strength degradation on safety and serviceability of structures due to aggressive environment. The role of periodic inspection and maintenance in enabling a target reliability level to be met over a period of continued service has also been considered.

\section{Discussion and Conclusions}

In most of the above models, service life of RC structures is divided in different phases. First conceptual model of service life has been provided by Tuutti in 1982. Tuutti's model divides service life in two phases: first phase represents the time required by chloride ion or carbonation to initiate the corrosion and second phase represents the time after corrosion initiation until structure fails.

From the above review it has been observed that Bayesian belief network models are simple to use and required input data can be easily obtained from the user. Fuzzy logic approach is the best for removing the uncertainties and imprecision in observed values. Markov chain models are useful when very few or no inspection data is available on severely deteriorated structures; however, it cannot account for unobserved durations and regular inspections of real structures are required for performing time-dependent reliability analysis. Semi-Markov process is one of the best ways to interpret the deterioration of structures subjected to harsh environments, as they consider different damage levels of the structures with different service lives. Weibull-based approach performs better in evaluating probability of failure.

Probabilistic models account well for the uncertainties in the parameters responsible for deterioration of RC structures. Therefore, because of the random nature of the parameters governing the performance of RC structures, probabilistic approach is better to develop reliable service life prediction model. Probabilistic models calibrated with monitored field data can provide more reliable models to predict the probabilities of corrosion.

\section{Conflict of Interests}

The authors declare that there is no conflict of interests regarding the publication of this paper.

\section{References}

[1] Z. Li, C. K. Chau, and X. Zhou, "Accelerated assessment and fuzzy evaluation of concrete durability," Journal of Materials in Civil Engineering, vol. 17, no. 3, pp. 257-263, 2005.

[2] Y. Li and T. Vrouwenvelder, "Service life prediction and repair of concrete structures with spatial variability," Heron, vol. 52, no. 4, pp. 251-267, 2007. 
[3] W.-M. Zhang and H.-J. Ba, "Accelerated life test of concrete in chloride environment," Journal of Materials in Civil Engineering, vol. 23, no. 3, pp. 330-334, 2011.

[4] W. Chai, W. Li, and H. Ba, "Experimental study on predicting service life of concrete in the marine environment," Open Civil Engineering Journal, vol. 5, no. 1, pp. 93-99, 2011.

[5] D. Vorechovska, B. Teply, and M. Chroma, "Probabilistic assessment of concrete structure durability under reinforcement corrosion," Journal of Performance of Constructed Facilities, vol. 24, no. 6, pp. 571-579, 2010.

[6] L. Parameswaran, R. Kumar, and G. K. Sahu, "Effect of carbonation on concrete bridge service life," Journal of Bridge Engineering, vol. 13, no. 1, pp. 75-82, 2008.

[7] S. Rostam, "Service life design of concrete structures: a challenge to designers as well as owners," Asian Journal of Civil Engineering, vol. 6, no. 5, pp. 423-445, 2005.

[8] B. Martin-Perez and Z. Lounis, "Numerical modeling of service life of reinforced concrete structures," in Proceedings of the 2nd International RILEM Workshop on Life Prediction and Aging Management of Concrete Structures, pp. 71-79, Paris, France, May 2003.

[9] A. Abu-Tair, C. McParland, J. F. Lyness, and A. Nadjai, "Predictive models of deterioration rates of concrete bridges using the factor method based on historic inspection data," in Proceedings of thof the 9th Durability of Building Materials and Components (DBMC '02), pp. 2621-2629, Brisban, Australia, 2002.

[10] B. Teply, "Modelling of deterioration effects on concrete structures," Acta Polymerica, vol. 42, no. 3, pp. 8-12, 2002.

[11] A. D. Orcesi and D. M. Frangopol, "Use of lifetime functions in the optimization of nondestructive inspection strategies for bridges," Journal of Structural Engineering, vol. 137, no. 4, pp. 531-539, 2011.

[12] D. Cusson, Z. Lounis, and L. Daigle, "Durability monitoring for improved service life predictions of concrete bridge decks in corrosive environments," Computer-Aided Civil and Infrastructure Engineering, vol. 26, no. 7, pp. 524-541, 2011.

[13] A. K. Agrawal, A. Kawaguchi, and Z. Chen, "Deterioration rates of typical bridge elements in New York," Journal of Bridge Engineering, vol. 15, no. 4, pp. 419-429, 2010.

[14] G. Mitra, K. K. Jain, and B. Bhattacharjee, "Condition assessment of corrosion-distressed reinforced concrete buildings using fuzzy logic," Journal of Performance of Constructed Facilities, vol. 24, no. 6, pp. 562-570, 2010.

[15] A. Strauss, K. Bergmeister, S. Hoffmann, R. Pukl, and D. Novák, "Advanced life-cycle analysis of existing concrete bridges," Journal of Materials in Civil Engineering, vol. 20, no. 1, pp. 9-19, 2008.

[16] G. C. Marano, G. Quaranta, and M. Mezzina, "Fuzzy timedependent reliability analysis of RC beams subject to pitting corrosion," Journal of Materials in Civil Engineering, vol. 20, no. 9, pp. 578-587, 2008.

[17] S. Tesfamariam and B. Martín-Pérez, "Bayesian belief network to assess carbonation-induced corrosion in reinforced concrete," Journal of Materials in Civil Engineering, vol. 20, no. 11, pp. 707-717, 2008.

[18] J. Sobhani and A. A. Ramezaninpour, "Modeling the corrosion of reinforced concrete structures based on fuzzy systems," in Proceedings of the 3 rd International Conference on Concrete and Development, pp. 729-741, Tehran, Iran, April 2009.

[19] R. E. Melchers, C. Q. Li, and W. Lawanwisut, "Probabilistic modeling of structural deterioration of reinforced concrete beams under saline environment corrosion," Structural Safety, vol. 30, no. 5, pp. 447-460, 2008.

[20] D. V. Val, "Deterioration of strength of RC beams due to corrosion and its influence on beam reliability," Journal of Structural Engineering, vol. 133, no. 9, pp. 1297-1306, 2007.

[21] M. B. Anoop and K. Balaji Rao, "Application of fuzzy sets for remaining life assessment of corrosion affected reinforced concrete bridge girders," Journal of Performance of Constructed Facilities, vol. 21, no. 2, pp. 166-171, 2007.

[22] L. Shao and C. Q. Li, "Reliability based asset management strategy for concrete infrastructure," International Journal of Materials and Structural Reliability, vol. 5, no. 1, pp. 13-28, 2007.

[23] S. Sasmal, K. Ramanjaneyulu, S. Gopalakrishnan, and N. Lakshmanan, "Fuzzy logic based condition rating of existing reinforced concrete bridges," Journal of Performance of Constructed Facilities, vol. 20, no. 3, pp. 261-273, 2006.

[24] C. Q. Li, W. Lawanwisut, and J. J. Zheng, “Time-dependent reliability method to assess the serviceability of corrosionaffected concrete structures," Journal of Structural Engineering, vol. 131, no. 11, pp. 1674-1680, 2005.

[25] J. S. Kong and D. M. Frangopol, "Sensitivity analysis in reliability-based lifetime performance prediction using simulation," Journal of Materials in Civil Engineering, vol. 17, no. 3, pp. 296-306, 2005.

[26] K. A. T. Vu and M. G. Stewart, "Predicting the likelihood and extent of reinforced concrete corrosion-induced cracking," Journal of Structural Engineering, vol. 131, no. 11, pp. 1681-1689, 2005.

[27] F. Akgül and D. M. Frangopol, "Lifetime performance analysis of existing reinforced concrete bridges. II: application," Journal of Infrastructure Systems, vol. 11, no. 2, pp. 129-141, 2005.

[28] D. V. Val, "Effect of different limit states on life-cycle cost of RC structures in corrosive environment," Journal of Infrastructure Systems, vol. 11, no. 4, pp. 231-240, 2005.

[29] M. G. Stewart and D. V. Val, "Multiple limit states and expected failure costs for deteriorating reinforced concrete bridges," Journal of Bridge Engineering, vol. 8, no. 6, pp. 405-415, 2003.

[30] C. Q. Li, "Life-cycle modeling of corrosion-affected concrete structures: propagation," Journal of Structural Engineering, vol. 129, no. 6, pp. 753-761, 2003.

[31] C. Q. Li, "Life cycle modeling of corrosion affected concrete structures-initiation," Journal of Materials in Civil Engineering, vol. 15, no. 6, pp. 594-601, 2003.

[32] M.-T. Liang, L.-H. Lin, and C.-H. Liang, "Service life prediction of existing reinforced concrete bridges exposed to chloride environment," Journal of Infrastructure Systems, vol. 8, no. 3, pp. 76-85, 2002.

[33] J. Gulikers, "Critical review of corrosion deterioration models for reinforced concrete," in Proceedings of the 9th Durability of Building Materials and Components (DBMC '02), pp. 0941-0910, Brisban, Australia, 2002.

[34] A. Abu-Tair, C. McParland, J. F. Lyness, and A. Nadjai, "Predictive models of deterioration rates of concrete bridges using the factor method based on historic inspection data," in Proceedings of the 9th Durability of Building Materials and Components (DBMC '02), p. 262, Brisban, Australia, 2002.

[35] K. Vu and M. G. Stewart, "Service life prediction of reinforced concrete structures exposed to aggressive environments," in Proceedings of the 9th Durability of Building Materials and Components (DBMC '02), p. 119, Brisban, Australia, 2002. 
[36] M. P. Enright and D. M. Frangopol, "Survey and evaluation of damaged concrete bridges," Journal of Bridge Engineering, vol. 5, no. 1, pp. 31-38, 2000.

[37] B. Naticchia, "Quality simulation for assessment of chemicalphysical compatibility among building components," Durability of Building Materials and Components, vol. 8, pp. 1457-1466, 1999.

[38] L. Scheremans and D. V. Gemert, "Service prediction of reinforced concrete structures, based on in-service, chloride penetration profiles," Durability of Building Materials and Components, vol. 8, pp. 83-93, 1999.

[39] B. Teply, D. Novak, Z. Kersner, and W. Lawanwisut, "Failure probability of deteriorating reinforced concrete beams," Durability of Building Materials and Components, vol. 8, pp. 13571366, 1999.

[40] M. P. Enright and D. M. Frangopol, "Condition prediction of deteriorating concrete bridges using Bayesian updating," Journal of Structural Engineering, vol. 125, no. 10, pp. 1118-1125, 1999.

[41] M. S. Cheung and B. R. Kyle, "Service life prediction of concrete structures by reliability analysis," Construction and Building Materials, vol. 10, no. 1, pp. 45-55, 1996.

[42] Y. Mori and B. R. Ellingwood, "Reliability-based service-life assessment of aging concrete structures," Journal of Structural Engineering, vol. 119, no. 5, pp. 1600-1621, 1993. 

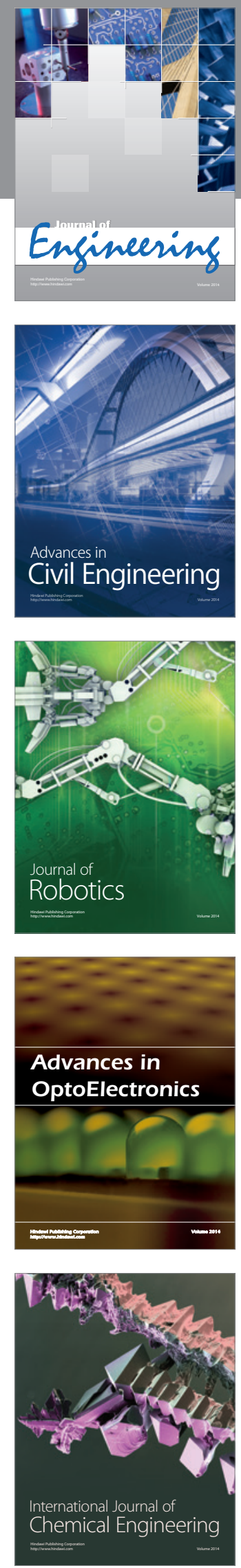

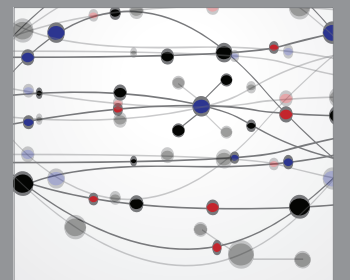

The Scientific World Journal
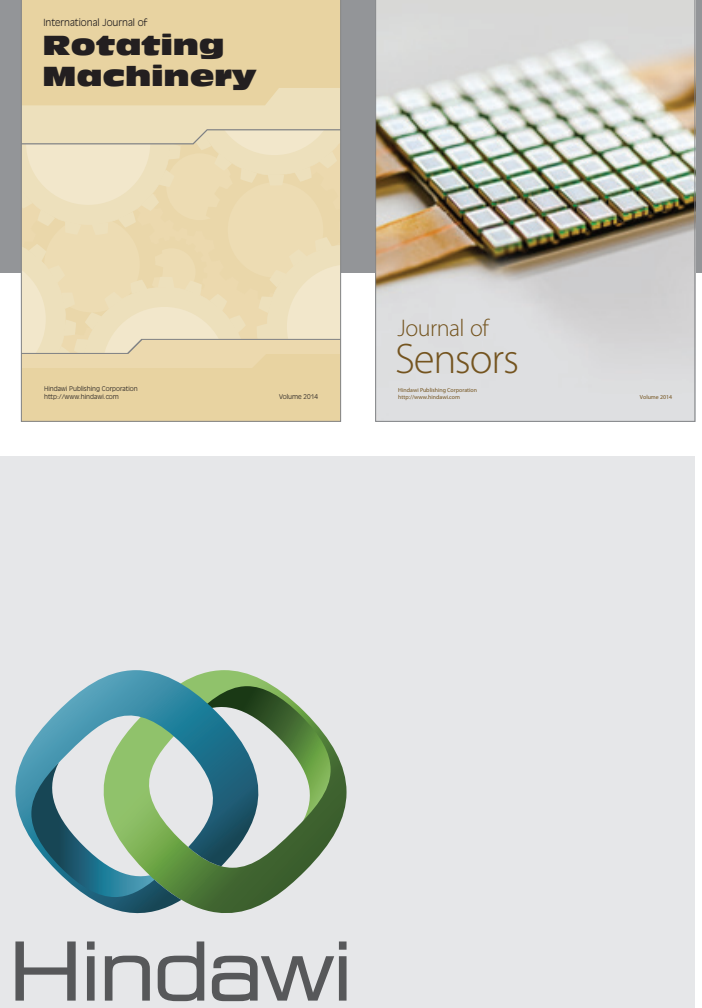

Submit your manuscripts at http://www.hindawi.com
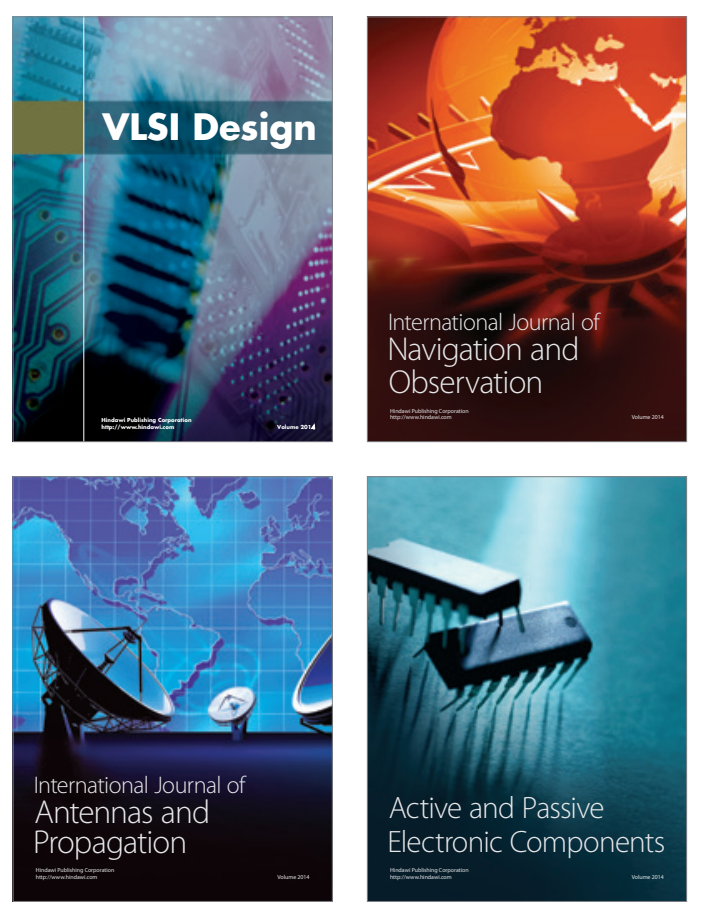
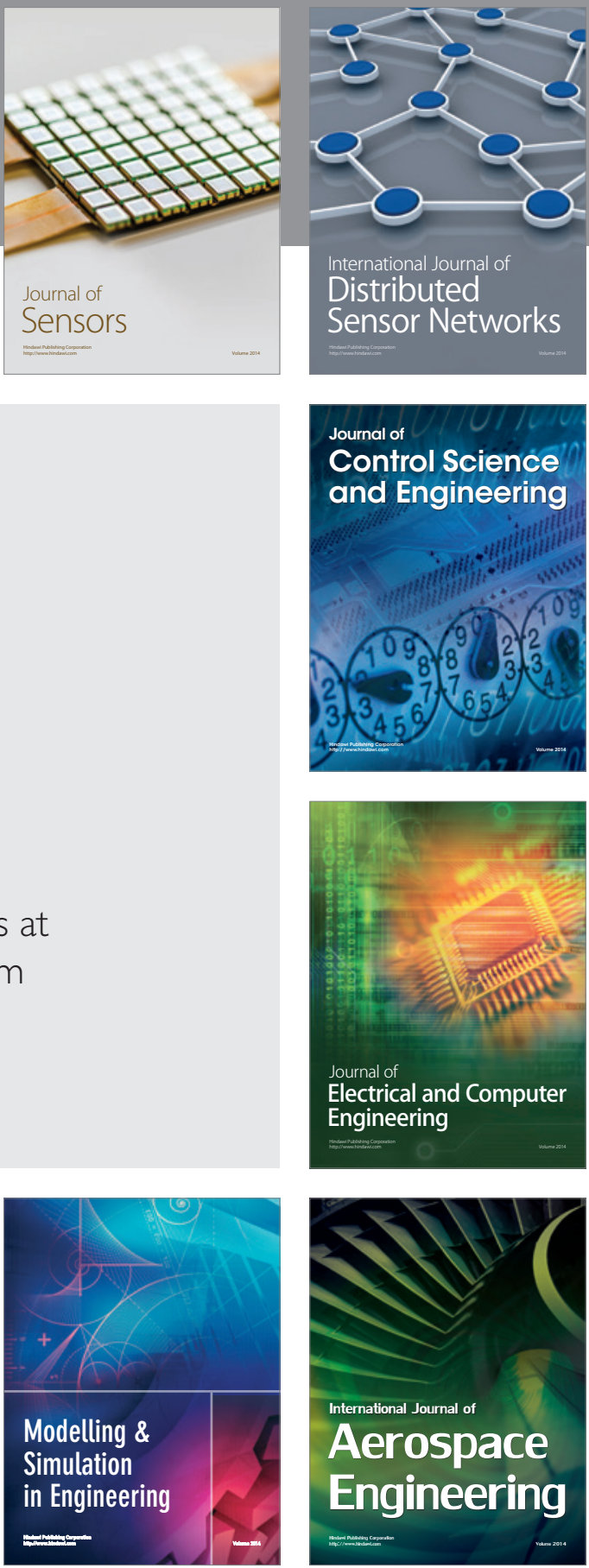

Journal of

Control Science

and Engineering
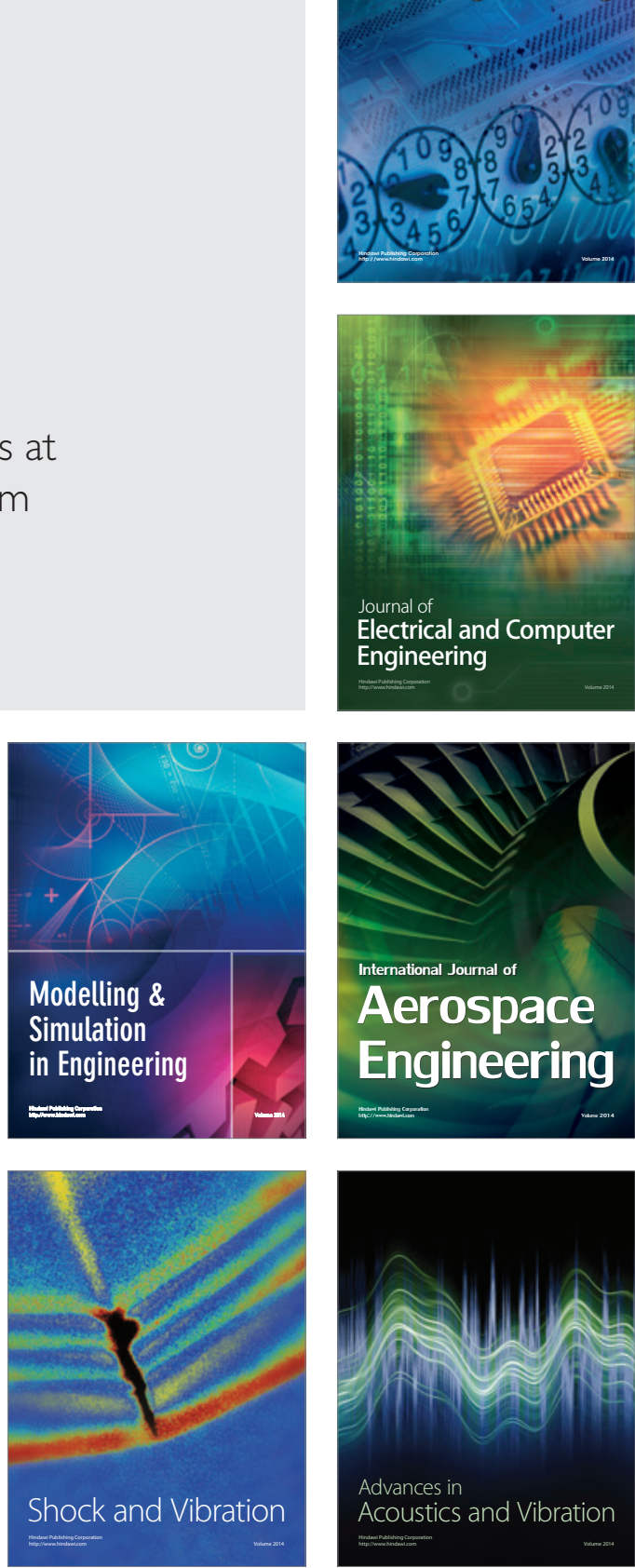